\title{
A Genetic Algorithm Basrd Problem Detection for Unit Commitment (UC) Problems
}

\author{
V.Lakshmi Devi, V.Joshi Manohar
}

\begin{abstract}
This recommendation watches out for the Unit Commitment (UC) issue, which be a notable combinatorial improvement issue climbing being made masterminding of intensity structures. In the UC issue, one wishes to structure a division of a particular system of age units with notwithstanding pick their age yield during regulate toward satisfy immensity needs by any rate cost larger than a specified instance prospect. Also, the framework should assure a great deal of mechanical along with stipulate imprisonments. The monstrous scale course of action of practical resources has starting late brought centrality up in advantageous techniques for submitting locational holds to affirm the structure against potential outcomes and the shocking and exceedingly factor shortcoming of reachable power source supply, while tending to power stream goals obliged through the broadcast make. during This paper we keep in mind frameworks designed for filing locational holds: stochastic unit determination moreover a mutt reinforce of situation manual protection-obliged willpower. This paper turns giving a recognizable assessment of the trendy method utilized in improving UC problems for each stochastic and deterministic hundreds, which has been gotten from special amigo examined dispersed papers. It has been limits into diverse factors which be a part of severa desires problem to preferred function, security, flood and time. This paper, proposes a go breed genetic algorithm is proposed to cope with the Unit Commitment $(U C)$ problem. It need to be reminded that in the $U C$ problem, one needs to layout a subset of a given get-cosllectively of electrical power age devices and other than to pick their age yield to satisfy centrality needs at any rate cost.
\end{abstract}

\section{INTRODUCTION}

Power structures are a standout among the most key establishments in a country since the thing included is head to standard normal proximity. Nowadays, its straightforwardness and cost are essential to various affiliations also, business [91, 92]. Beginning late, the power age industry has seen mind blowing improvement. In light of the advancement of economy and most absurd, the Usage of energy is rising. In the previous 10 years (from 2000 to2010), inside the Euro region, the improvement has been about $13 \%$, at the same time as in Portugal it is been about $25 \%$, as it will the whole lot taken into consideration be determined in Figure 1.1. With the developing criticalness of the development the electricity branch plays within the impelled, an epic extent of exertion has been placed into shape up an attested, stable and budgetary power deliver. The Unit dedication is essential in accomplishing this intention, therefore the opportunity of its answer is of the maximum critical centrality. The examination and mission of energy structures breaker managing a wide level of update issues.
Among these issues, the Unit Commitment (UC) issue creates as it see a key occupation in engineering and working force structures. The effect age industry uses unit obligation and cash related dispatch to help pick age booking choices. An ideal structure of the creation units has the cutoff of sparing a goliath number of euros. The target of a UC issue is to see a timetable of submitting units to keep the joint expense of submitting and decommitting units and money related dispatch. Meanwhile, it satisfies the picked need and turning spare necessities, that consider nonappearance of affirmation pay and mechanical making unit confinements.

The expanding meagerness of power structure rehearses in light of the beast scale coordination of reasonable power source Resources and contact for response has introduced an essentialness up in useful frameworks for submitting day-ahead shops so that it will paintings the form dependably. Standard additional dedication techniques [1] depend upon additional requirements and security receives which may be proposed to straightforwardness consistent risks in demand and boundless supply correspondingly as discrete aggravations, for instance, generator and transmission line frustrations. In any case, these models reliably expulsion to get the full level of multifaceted nature in a deficient condition and depend rather on heuristic practices gotten by chiefs through experience. 


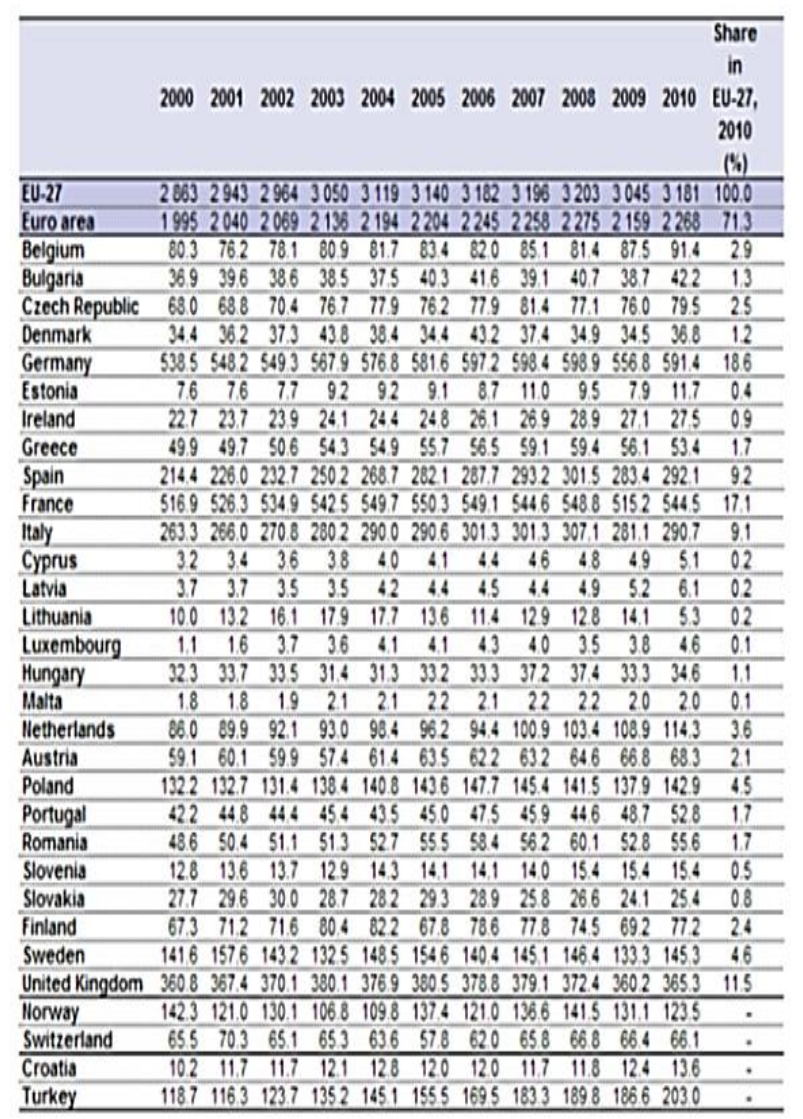

\section{Figure 1.1: Net electricity generation, in thousands of GWh, in Europe for 2000-2010.}

With the assist of this replace, it's miles feasible to deliver control with least ability hardships and least gasoline use, to help the bit of slack. Other than accomplishing least complete introduction charge, an age timetable desires to satisfy isolating strolling objectives. These necessities decrease opportunity inside the desire of starting off and last down of making gadgets. The dreams to be happy are continuously the recognition the front of individual making gadgets, least up time, least down time, restriction limits, age restriction for the first and an hour decrease lower back, stored examination price, percent want, control stability necessity, turning spare focal, alongside those lines ahead. The immoderate dimensionality and combinatorial nature of the UC trouble packs the undertakings to expand any raised canny improvement thinking fit for dealing with the whole issue for any certified size structure. Adventitiously, in the piece, various structures using a sort of check and updates have been proposed.

\section{PROBLEM DESCRIPTION}

As it was by then passed on, the UC issue joins an immense measure of age Devices for which one desires to select out whilst each unit is on-line and disengaged alongside a predefined time horizon. In like way, for every time run and every on-line unit it's far aside from picked all it should make. Everything considered, the trouble wires styles of choices, which are certain thru two forms of necessities: load obstructions and revolutionary ones. Since on a rushed degree there are numerous diagrams pleasing the goals, one need to depict a show degree, which ordinary is the minimization of the inconvenient charges brought on with the challenge of the appearance devices and the age of the specified strength. The popular unit obligation trouble, the maximum routinely paid surprising person to get-collectively, is a deterministic unmarried target improvement problem. Far is the minimization of the entire scale operating charges over the shape horizon. Certainly the running fees can be passed on as the overall of the fuel, shutdown and begin-up charges. Structure vulnerabilities are tended to through deterministic maintain techniques, which maintain up more to be a positive diploma of the summit load. The stochastic natures of depth systems are all things considered showed up in the improvement issues.

Other UC issue courses of action including additional complexities, and possibly enough changed by current criticalness cash related conditions, have in like way been considered in the piece. Among the different issues considered in the affiliation we paid historic character to the shocking releases issue. The choice of the contaminations issue is routinely a brief yielded delayed consequence of the way that, everything considered, standard concerns have been getting centrality. A couple of various procedures for instinct concerning wrecking have been proposed by the viewpoint makers. For example, controls on sullying gases, for instance, $\mathrm{CO} 2$ have been solidified, degradation settlements have been executed, an inside market for carbon dioxide stipends has been set up by the European Union (where affiliations can buy or sell dirtying rewards).

\section{UC PROBLEM SOLVING TECHNIQUES}

UC is the issue of picking the timetable of making units inside a power structure subject to contraption and working constrainments. Two or three update frameworks have been connected with find the response for the warm UC issue. The plans open are referenced into standard structures, non-standard frameworks for sense and cream algorithm.

\subsection{Conventional structure}

Customary structures strip concentrated association, need posting, dynamic programming, branch and bound, integer programming, reenacted supporting, Lagrangian discharging up, tabu interest, and inside point update. The thorough check suffering is silly unordinary of the combinatorial improvement system. The standard of this structure is to audit all mixes of the discrete parts. It ensures the general faultless of the objective work, yet the computational time is titanic [8]. Branch and bound (BB or B\&B) is a general algorithm for discovering perfect relationship of various update issues, especially in discrete and combinatorial improvement. This framework was first proposed through Land and Doig Dynamic programming is an adroit structure, which purposefully considers wearisome potential decisions in a multi-step issue. Completely when the present standard striking programming structure is utilized, paying little notice to how its answer is correct and has the perfect worth, it takes an immense degree of memory and takes a goliath level of 
time in getting a perfect framework. Mixed Integer Linear Programming (MILP) diminishes the structure in a general sense and in like way the nonlinear constrainments can be sensibly linearised. The MILP UC inspiration driving control made by Chang et al. can be used for awesomely mammoth structures which other than assistance offering systems in the power market.

The vivified toughening (SA) framework partakes in looking through the work space quickly, yet it doesn't work fittingly by tolerability of wide temperature gathering. In the basic SA structure, a goliath bit of the figuring time was spent in discretionarily making and inspecting points of view that devilishness up being infeasible. To improve the introduction, a mix of SA and close intrigue was made in 2003 by Purushothama et al. also, the outcomes were checked utilizing $\mathrm{C}++$. This undeniable change makes it conceivable to diminish the level of emphasess required at every temperature, and it makes approaches with lower cost than that checked by utilizing past algorithms. Lagrangian sterilizing up was at first connected with UC in 1977 by Muckstadt et al.. The issue is figured like a cost most remote point, that is the entire of terms each including a solitary unit, a goliath level of objectives including a particular unit, an immense degree of coupling bases on (the age and extra necessities), one for unendingly in the examination time run, including all units.

\subsection{Non standard (Non old style) systems}

The genetic algorithm (GA) is an absolutely gigantic, clear and overpowering, stochastic and parallel systems structure subject to the mechanics of fundamental choice and standard Genetics. The GA works with a hundreds of chromosomes. A chromosome is an improvement of bits zero and 1. Mother et al. Proposed an advanced GA shape the usage of $\mathrm{C}++$ system in 2011. This technique was had a cross at making use of $\mathrm{C}++$ on a 6 unit shape over a booking time of 6 hours. Abookazemi and Mustafa constructed up a parallel form to improved GA which gives an affecting clear for after and in like manner constantly head economic gadget in 2009. This form become made and endeavored by using using using C\# software. Tests were finished on 10 and 20 devices systems over a booking time of 24 hours. Atashpaz-Gargari et al. First validated the imperialistic take a imperialistic test algorithm (ICA) in 2007. In the ICA, the confirmed masses people (nations) are in two sorts: voyagers and locale that all together structure a couple of spaces. The imperialistic rivalries among these territories unite to a state, where there exists just a single space.

\subsection{Stochastic Unit Commitment}

The stochastic showing up for after The model of Ruiz et al. [6] and units a -make machine, where the form of ugly situations is tended to as $S$ with each situation $\mathrm{s} € \mathrm{~S}$ taking place with a chance $\pi$ s. First-engineer unit commitment and startup alternatives are paid unique mind to self-governingly as $\mathrm{w}$ and $\mathrm{z}$ and practice for those generators Gs for which dedication picks have to be positioned aside two or $3 \mathrm{mins}$, within the day-in advance time duration. The hassle to be comprehended is the going with: control the infeasibility difficulty in a controlled and

$$
\begin{aligned}
& (S U C): \\
& \min _{p, e, u, v, w, z} \sum_{g \in G} \sum_{s \in S} \sum_{t \in T} \pi_{s}\left(K_{g} u_{g s t}+S_{g} v_{g s t}+C_{g} p_{g s t}\right) \\
& \text { s.t. } \sum_{g \in G_{n}} p_{g s t}=D_{n s t}, n \in N, s \in S, t \in T \\
& P_{g s}^{-} u_{g s t} \leq p_{g s t} \leq P_{g s}^{+} u_{g s t}, g \in G, s \in S, t \in T \\
& e_{k s t}=B_{k s}\left(\theta_{n s t}-\theta_{m s t}\right), k=(m, n) \in K, s \in T, \\
& t \in T \\
& (\mathrm{p}, \mathrm{e}, \mathrm{u}, \mathrm{v}) \in \mathcal{D}_{s}, s \in S \\
& u_{g s t}=w_{g t}, v_{g s t}=z_{g t}, g \in G_{s}, s \in S, t \in T
\end{aligned}
$$

\section{GENETIC ALGORITHMS}

Genetic algorithms is a general quest for after heuristic, which makes answers for streamlining issues utilizing systems vivified by standard progress, for example, change, accreditation, and crossbreed. The GA's quality be joined into an always wide Elegance of the transformative algorithms (EA). Everything considered, a masses of the chromosomes (besides known as humans or phenotypes) is taken and have to make to join the tremendous plans. During the developmental tool, each character may be in risk to validation, exchange and bypass breed genetic heads. Usually, philosophies are may want to even as all is said in finished in parallel as strings of zero and 1 respects or using skimming element plot, or maybe, as string of actual developments. With everything taken into consideration, the simple people is randomly handed on. In every age, the flourishing of anybody inside the greater element is surveyed. Next, a diploma of the general community within the gift humans with higher accomplishment can be emphasized to the brand new hundreds, each other degree are stochastically gotten some data about the existing human beings, and each man or woman genome is recombined and randomly changed to chart some other hundreds. Likewise, in express fashions, it'd appear vexatious affiliation. The improvement can be applied to keep up the now not especially annoying approach of the techniques in the massive open and, in this manner, enhance the presentation of the genetic set of rules [3]. The development concretes confirming a predetermined stage of the overall open for the new human beings, thru randomly age, loads uncertain from the case for the secured hundreds. The new individuals is then applied inside the pinnacle degree age of the set of regulations. The most all around applied genetic specialists are the choice, trade and skip breed. The mutt awards to unite the gatekeepers alleles circling some other chromosome string that gets homes from the two watchmen. The change is carried out to maintain up genetic created amassing from one age of a hundreds of people to the going with. At each age: a given level of people inside the gift masses is picked to weight the overall open of

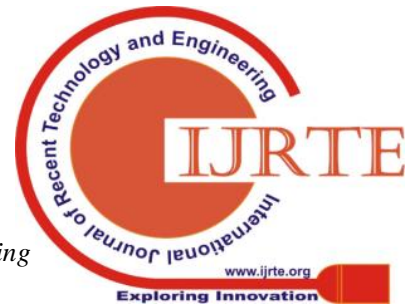


the going with loads, yielding a pool of the exhaustive network. The preference of the overall open is probably completed via random checking out or challenge to their flourishing profound admire in which the great strategies are in maximum instances picked. Next, a pair the gatekeepers are investigated the pool starting overdue picked getting a technique is repeated until a diploma of the trendy young human beings humans is gotten. The bypass breed is a technique from which multiple determine frameworks impersonates a pre-grown-up approach. There are unmistakable combination modalities, as an example, the one-factor pass breed, -factor mutt and uniform taste. In the single cream element, the adolescent is checked within the going with manner: all allele respects from start of chromosome to the mixture point are reproduced from one determine, the remainder of the parts alleles respects are rehashed from the ensuing watchman.

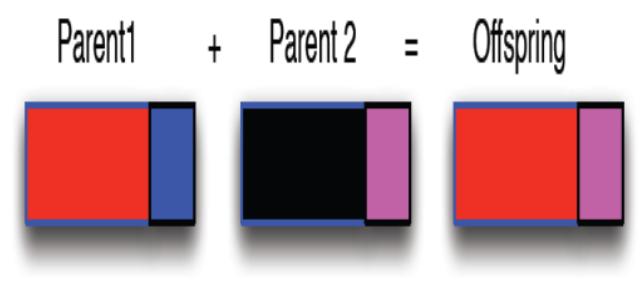

Figure 4.1: Single Point Crossover.

In the two-point cross breed, the allele respects from start of chromosome to the essential blend point are repeated from one parent, the part from the first to the accompanying cream point is copied from the resulting gatekeeper and the remainder of the parts alleles respects are emphasized from the central parent.

\section{THE PROPOSED METHODOLOGY}

All around exceptional heuristic improvement approachs have been made, a standout among The most extremely good being GAs. Dependably, GAs improve a masses of strategies due to the fact the quit result of affirmation, question, and recombination. Cream and alternate are applied to keep up a opportunity sport-plan of the pushing human beings and thusly, get away from community optima. A couple of GAs have been proposed for the UC issue, see e..g.. Beginning at now passed on, GAs are a befuddling stochastic standard talking interest structure as the intrigue is performed by mishandling data attempted from various zones of the procedure space. Everything considered, GAs customarily utilize least from the past learning and removal to manhandle neighborhood data. Close Search algorithms begin with a fundamental blueprint and try to achieve an ideal technique by structures for little undertakings to the cadenced improvement approach, that is, the intrigue is done inside a pre-appeared. The likelihood of a Local Search structure into a GA Automatically activates liberal development for the reason that "close by" broaden uttermost scopes of the beyond are being united with the "around the world" idea of the GA. GAs with random keys have been first confirmed up through [9], for planning sequencing problems. In choppy few different character (tyke) via mutt and change. This don't perform well in growing close ideal plans since they

random key GAs, the affinity is had all of the earmarks of being clean ranges. From one element of view, while guardians are picked, fantastic frameworks have a better reliability of being picked, when you consider that one of the gatekeepers is constantly taken from a subset together with the awesome approachs. Then again, the mutt shape is sure to pick out alleles from the high-quality determine to be avowed by using way of family.

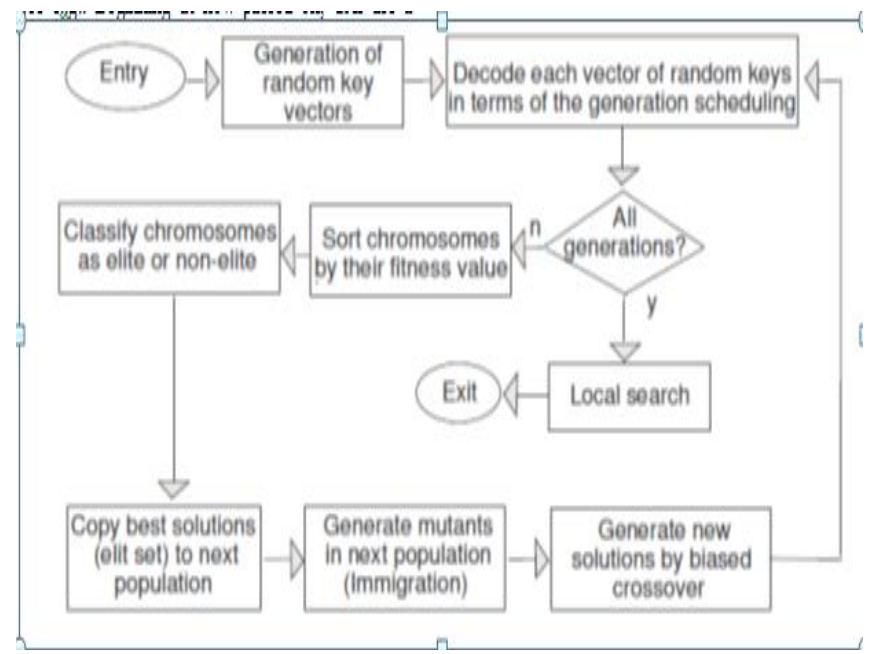

Figure 5.1: The HBRKGA adapted framework

\subsection{Handling infeasibilities}

Since BRKGA is a standard referencing system, in the use of this GA to the obliged UC progress issue we in like way solidify a region to fix UC approaches. The fixing approach changes what may be an infeasible methodology into a conceivable diagram. The standard clarification behind using a fix strategy in Genetic Algorithms is the decrease of the interest space to feasible procedures. In spite of the way by which that control cutoff focuses are the least irritating and most all around used structures for directing targets in Evolutionary Algorithms (EAs), they have a few squares. The standard trouble is that control factors which pick truth of the requesting, must be set by the customer and their characteristics are issue subordinate

$$
\begin{gathered}
\tilde{f}(x)=\frac{f(x)-f_{\text {min }}}{f_{\text {max }}-f_{\text {min }}} . \\
f(x)=\sum_{t=1}^{T} \sum_{j=1}^{N}\left(F_{j}\left(y_{t, j}\right) \cdot u_{t, j}+S_{t, j} \cdot\left(1-u_{t-1, j}\right) \cdot u_{t, j}+S d_{j} \cdot\left(1-u_{t, j}\right) \cdot u_{t-1, j}\right),
\end{gathered}
$$

\subsection{GA Configuration}

To get another masses of techniques, we join 3 subsets of approachs got as outputs for after:

_ Copied Solutions: $20 \%$ of the best plans of the extent of tenants in the present age (top of the line set) are imitated onto the broad framework to come;

_ Mutants: $20 \%$ of the plans of the extent of occupants in the forefront are gotten with no other individual's information unequivocally making new frameworks.

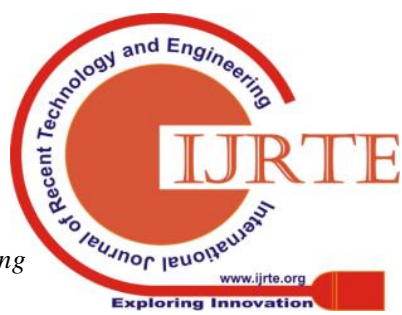


_ Offspring Solutions: $60 \%$ of the plans of the extent of occupants in the forefront are gotten by uneven age, which is cleaned by using both an uneven parent decision and an uneven mix probability.

\section{NUMERICAL RESULTS}

6.1 Test system

In order to show feasibility of GA for mindfulness

UCP, it's far related to check approach of eight gadgets ( $n$ = eight) after a few period of eight hours ( $\mathrm{t}=$ eight) [1].

\begin{tabular}{|c|c|c|c|c|c|c|c|c|}
\hline Hour $(\mathrm{t})$ & 01 & 02 & 03 & 04 & 05 & 06 & 07 & 08 \\
\hline $\mathrm{PD}_{1}(\mathrm{MW})$ & 400 & 470 & 520 & 510 & 360 & 240 & 240 & 450 \\
\hline $\mathrm{PD}_{\mathrm{j}}+\mathrm{R}_{\mathrm{j}}(\mathrm{MW})$ & 450 & 530 & 600 & 540 & 400 & 280 & 290 & 500 \\
\hline
\end{tabular}

Table 1. Load demand and reserve requirement of test system

\begin{tabular}{|c|c|c|c|c|c|c|c|c|c|}
\hline \multirow{2}{*}{ Unit n } & \multirow{2}{*}{$P_{\max }$} & \multirow{2}{*}{$\mathrm{MUT}_{i}$} & \multirow{2}{*}{$\mathrm{MTD}_{i}$} & \multirow{2}{*}{ IC } & \multirow{2}{*}{$\begin{array}{l}\text { AFLC I } \\
\text { MWh }\end{array}$} & \multirow{2}{*}{$\mathrm{SDC}_{i}$} & \multicolumn{3}{|c|}{$\mathrm{SUC}_{3}$} \\
\hline & & & & & & & $b_{1 i}$ & $b_{1 i}$ & $b_{3}$ \\
\hline 1 & 080 & 3 & 2 & -1 & 20.88 & 0 & 0350 & 158.00 & 0.400 \\
\hline 2 & 250 & 2 & 1 & -2 & 18.00 & 0 & 0400 & 162.62 & 0.900 \\
\hline 3 & 300 & 4 & 2 & 1 & 17.46 & 0 & 1100 & 421.18 & 0.480 \\
\hline 4 & 060 & 2 & 3 & -4 & 23.80 & 0 & 0.02 & 000.02 & 0.018 \\
\hline
\end{tabular}

Table 2. Generating unit characteristics of test system

\subsection{Simulation results with GA base approach to test system}

The errands are made the use of MATLAB programming and GA parameters used are, Crossover chance: 0.Sixty 5,
Mutation opportunity: zero.01, Number of a long time: 50, Elitism: three

Table 3. Result for test system with GA based approach

\begin{tabular}{|c|c|c|c|c|c|c|}
\hline \multirow{2}{*}{ Hour $j$} & \multicolumn{4}{|c|}{$S_{i j}$} & \multirow{2}{*}{$\mathrm{P}_{\mathrm{j}} \mathrm{MW}$} & \multirow{2}{*}{$\mathrm{OC}_{\mathrm{j}}$} \\
\hline & $i=1$ & $i=2$ & $i=3$ & $i=4$ & & \\
\hline 01 & 0 & 1 & 1 & 0 & 550 & 09966 \\
\hline 02 & 0 & 1 & 1 & 0 & 550 & 09738 \\
\hline 03 & 0 & 1 & 1 & 1 & 610 & 11166 \\
\hline 04 & 0 & 1 & 1 & 1 & 610 & 11166 \\
\hline 05 & 1 & 0 & 1 & 1 & 440 & 08797 \\
\hline 06 & 1 & 1 & 0 & 0 & 330 & 06570 \\
\hline 07 & 1 & 1 & 0 & 0 & 330 & 06170 \\
\hline 08 & 0 & 1 & 1 & 0 & 550 & 10838 \\
\hline Cumulativ & in In & $n$ Rup & $(\mathrm{INR})$ & & & 74411 \\
\hline
\end{tabular}

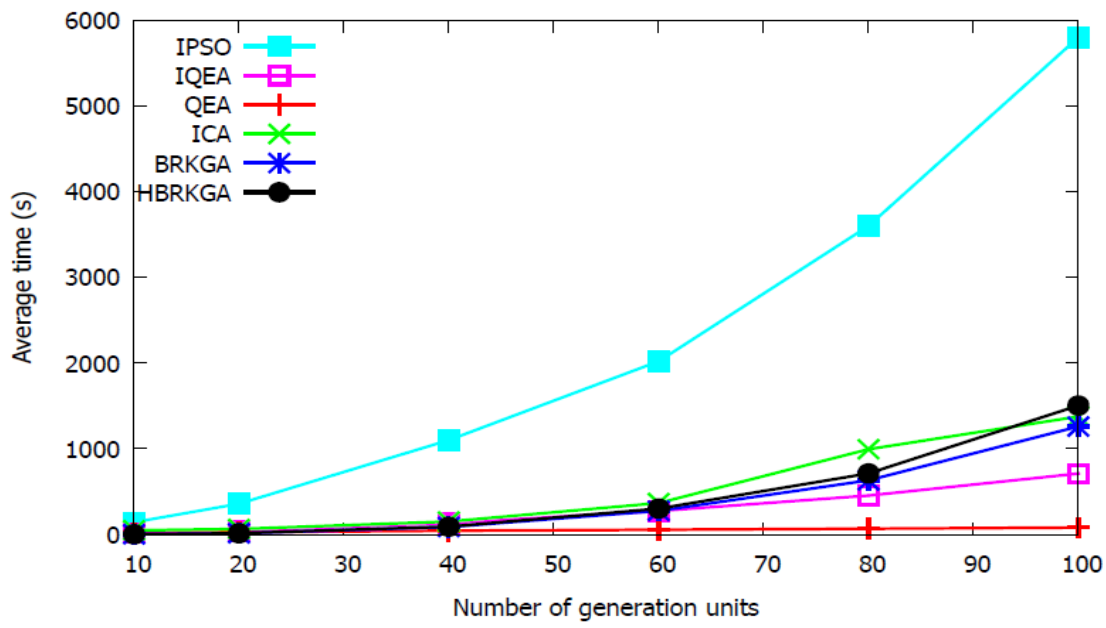

Figure 6.1: Computational time requirements. 


\section{CONCLUSION}

This paper demonstrates an examination on thought of the UC issue and frameworks proposed for lighting up it. In plan methodology, more bits of data concerning the beginning late made. Genetic algorithms has been given. These frameworks guarantees the creation plainly of development that don't violet structure or unit controls; to the extent that there are generators open within the solicitation pool to meet the require weight want. Despite how the general optimality is attracting, yet in most satisfying instances close immaculate plans is essentially appealing. This paper endeavors to find the high-quality timetable from a first rate degree of particular conceivable duty alternatives. The result suggests that it's miles viable to acquire updates the use of the ones framework.

\section{REFERENCES}

1. A. J. Wood and B. F. Wollenberg, 'Power generation operation and control', John Wiley and sons (Asia), second edition, 2006.

2. A. Perlin and P. Sandrin, 'A new method for unit commitment at Electricite De France', IEEE Transaction on Power apparatus and system, Vol. PAS-102, No. 5, May 1983, pp 1218-1225.

3. B. Gerald, Sheble and George N. Fahd, 'Unit Commitment Literature Synopsis' IEEE Transactions on Power System, Vol.9, No.1, Feb 1993, pp 128-133.

4. Chuan-Ping Cheng, Chih-Wen Liu \& Chun-Chang Liu, 'Unit commitment by Lagrangian relaxation \& Genetic Algorithms', IEEE Transaction on Power system, Vol.15, No.2, May 2000, pp 707-714.

5. D. Dasgupta, and D.R. McGregor, 'Thermal Unit Commitment Using Genetic Algorithms' IEEE proceedings on Generation, transmission and distribution, vol 141, no 5, 1994, pp 459-465.

6. David E. Goldberg, 'Genetic algorithms in search, optimization and machine learning', Pearson Education Asia, 2001.

7. Dipankar Dasgupta, 'Unit Commitment in Thermal Power Generation Using Genetic Algorithm', In proceeding of the Sixth International Conference on Industrial and Engineering application of Artificial Intelligence and expert system (IEA/AIE-98), Edinburgh, UK, June 1-4-1993, pp 374-383. 